\title{
An elderly patient of formalin poisoning presenting with hematemesis
}

Umid Kumar Shrestha, ${ }^{a, b *}$ Subash Sapkota, ${ }^{a, b}$ Prakash Thapa, ${ }^{a, b}$

${ }^{a}$ Manipal College of Medical Sciences \& Manipal Teaching Hospital, Pokhara, Nepal ${ }^{b}$ Kaski Sewa Hospital and Research Center, Pokhara, Nepal

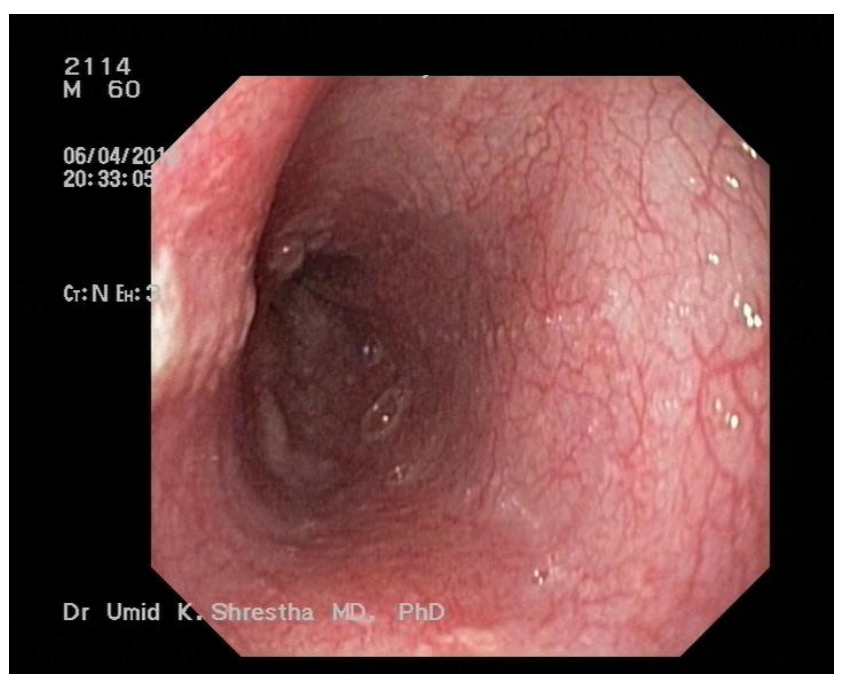

Figure 1. Esophagus (normal)

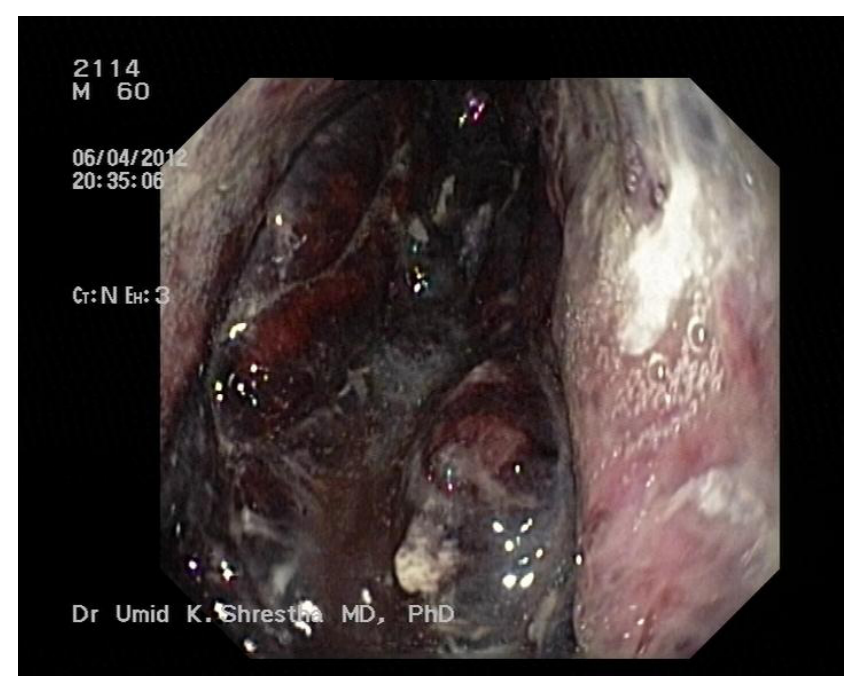

Figure 2. Stomach (completely charred mucosa: the rarest picture)

\section{DOI Name}

10.3126/jaim.v1i2.6527

\section{Keywords}

formalin, endoscopy

\section{Citation}

Shrestha UK, Sapkota S, Thapa P. An elderly patient of formalin poisoning presenting with hematemesis. Journal of Advances in Internal Medicine 2012;01(02):64.

* Corresponding author

Department of Medicine,

Manipal College of Medical Sciences \& Manipal Teaching Hospital, Pokhara, Nepal

Email address - umidshrestha@gmail.com

\section{CASE}

A 60-year-old male was admitted on April 6, 2012 to Kaski Sewa Hospital and Research Center, Pokhara, Nepal with a history of hematemesis. He had three episodes of vomiting of blood, each bout of vomitus containing about $100 \mathrm{ml}$ of blood. He was non-alcoholic and non-smoker. He denied having any liver disease in the past. He had been taking medicines for some psychiatric illness. On reviewing the history, the patient admitted that he had ingested some liquid material accidentally prior to the episode of blood vomiting, but could neither bring the substance nor tell its name.

At the time of presentation, pulse was 92/minute, blood pressure was $100 / 70 \mathrm{~mm} \mathrm{Hg}$ and abdomen was soft and non-tender without any organomegaly. Laboratory studies revealed elevated serum creatinine $(3 \mathrm{mg} / \mathrm{dl})$, reduced hemoglobin $(8 \mathrm{gm} / \mathrm{dl})$, elevated white blood count $(25,000 / \mathrm{cmm}$ with neutrophil $78 \%$, lymphocyte $20 \%$, monocyte $2 \%$ ), normal platelet count and normal liver function test. Other investigations showed normal coagulation tests with a normal prothrombin time (international normalized ratio, 1.1) and partial thromboplastin time (30 seconds with normal value ranging from $24-36$ seconds).

Upper gastrointestinal (UGI) endoscopy revealed normal esophagus (figure 1), but the mucosa of stomach was completely charred with the color turning brownish black and the mucosa around the pylorus was edematous causing the gastric outlet obstruction (figure 2).

Considering his clinical and imaging findings, what substance the patient might have ingested and how could it be treated?

Answer on page 68 
18. Cazeau S, Leclereq C, Lavergne T, et al. Multisite Stimulation in Cardiomyopathies (MUSTIC) Study Investigators. Effects of multisite biventricular pacing in patients with heart failure and intraventricular conduction delay. N Engl J Med 2001;344:87380.

19. Moss AJ, Hall WJ, Cannom DS, et al. Cardiac - resynchronization therapy for the prevention of the heart - failure events. $N$ Engl J Med 2009;361:1329-38.

20. Arshad A, Moss AJ, Foster E, et al. Cardiac resynchronization therapy is more effective in women than in men: the MADIT CRT (Multicenter Automatic Defibrillator Implantation Trial with Cardiac Resynchronization Therapy) trial. J Am Coll Cardiol 2011; 57:813-20.
21. Cleland JG, Daubert JC, Erdmann E, et al. The effect of cardiac resynchronization on morbidity and mortality in heart failure. $N$ Engl J Med 2005;352:1539-49.

22. Bristow MR, Saxon LA, Boehmer J, et al. Cardiac resynchronization therapy with or without an implantable defibrillator in advanced chronic heart failure. N Engl J Med 2004;350:2140-50.

23. Lindenfield J, Albert NM, Boehmer JP, et al. For the Heart Failure Society of America. Executive summary: HFSA 2010 comprehensive heart failure practice guideline. J Card Fail 2010:166:e1194.

\section{ANSWER \\ Formalin poisoning}

The UGI endoscopy done at the time of presentation had shown that the patient might have ingested some corrosive substance. On reviewing the history again, it was found that the patient had ingested $50 \mathrm{ml}$ of formalin ( $40 \%$ solution of formaldehyde in water). The patient was treated conservatively with bowel rest, intravenous (IV) nutrition supplement, IV proton pump inhibitor, IV antibiotic and blood transfusion. The serum creatinine level, white blood cell and hemoglobin returned to normal range after 3 days of treatment. This is a case of formalin poisoning with the strange endoscopic finding, which was unusual in the sense that there was completely normal esophagus, but the presence of severely burnt gastric mucosa. The UGI endoscopy was repeated after 4 weeks of treatment with a full bowel rest to the patient. The repeat endoscopy after 4 weeks was normal (figure 3 ) with no traces of burn injury to the mucosa. Gastric outlet obstruction has been described as the late complication of formaldehyde ingestion. ${ }^{1}$ In our case, after a follow up of 12 weeks, the patient was doing well and did not develop any features of gastric outlet obstruction or other late complication.

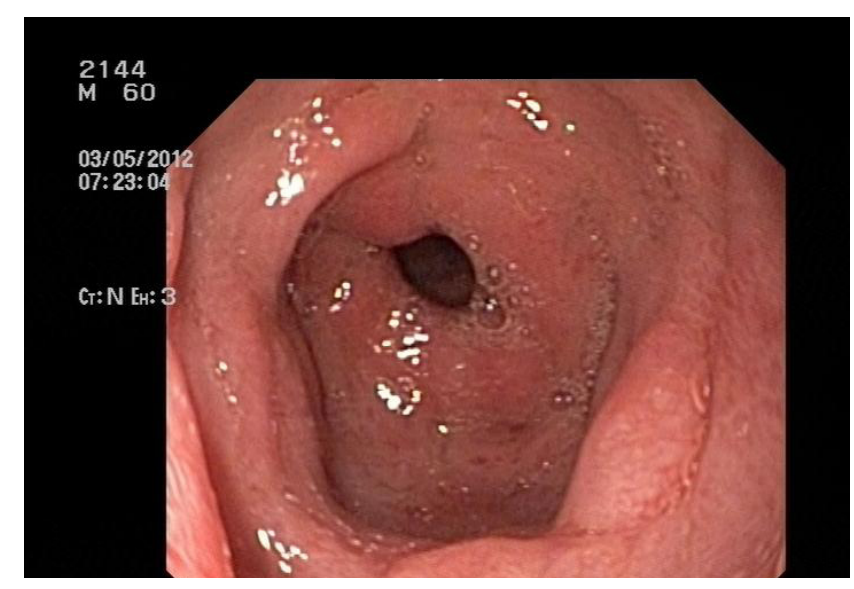

Figure 3. Stomach (normal mucosa, after four weeks of treatment)

Formaldehyde poisoning has been described previously by some authors. ${ }^{2,3}$ The few signs and symptoms that develop following the ingestion of formaldehyde are severe abdominal pain, retching, development of seizures, hypotension and difficulty in breathing. To our knowledge, this is the first report of formalin poisoning presenting with hematemesis, having the finding of normal esophagus, but severely burnt gastric mucosa, which returned to completely normal condition after a 4 week of bowel rest and other conservative treatment.

\section{REFERENCES}

1. Hawley CK, Harsch HH. Gastric outlet obstruction as a late complication of formaldehyde ingestion: a case report. Am J Gastroenterol 1999;94:2289-91.

2. Kochhar R, Nanda V, Nagi B, et al. Formaldehyde-induced corrosive gastric cicatrization: case report. Hum Toxicol 1986;5:381-2.

3. Köppel C, Baudisch H, Schneider V, et al. Suicidal ingestion of formalin with fatal complications. Intensive Care Med 1990;16:212-4. 